\title{
Detection and mapping of polar stratospheric clouds using limb scattering observations
}

\author{
C. von Savigny, E. P. Ulasi, K.-U. Eichmann, H. Bovensmann, and J. P. Burrows \\ Institute of Environmental Physics and Remote Sensing (IUP/IFE), University of Bremen, Otto-Hahn-Allee 1, 28334 \\ Bremen, Germany
}

Received: 8 April 2005 - Published in Atmos. Chem. Phys. Discuss.: 22 August 2005

Revised: 20 October 2005 - Accepted: 3 November 2005 - Published: 16 November 2005

\begin{abstract}
Satellite-based measurements of Visible/NIR limb-scattered solar radiation are well suited for the detection and mapping of polar stratospheric clouds (PSCs). This publication describes a method to detect PCSs from limb scattering observations with the Scanning Imaging Absorption spectroMeter for Atmospheric CartograpHY (SCIAMACHY) on the European Space Agency's Envisat spacecraft. The method is based on a color-index approach and requires a priori knowledge of the stratospheric background aerosol loading in order to avoid false PSC identifications by stratospheric background aerosol. The method is applied to a sample data set including the 2003 PSC season in the Southern Hemisphere. The PSCs are correlated with coincident UKMO model temperature data, and with very few exceptions, the detected PSCs occur at temperatures below 195-198 K. Monthly averaged PSC descent rates are about $1.5 \mathrm{~km} /$ month for the $-50^{\circ} \mathrm{S}$ to $-75^{\circ} \mathrm{S}$ latitude range and assume a maximum between August and September with a value of about $2.5 \mathrm{~km} /$ month. The main cause of the PSC descent is the slow descent of the lower stratospheric temperature minimum.
\end{abstract}

\section{Introduction}

Polar stratospheric clouds are of fundamental importance for the formation of the Antarctic ozone hole (Farman et al., 1985 ) that occurs every year since the early 1980s in Southern Hemisphere spring. PSCs act as hosts for heterogeneous reactions that transfer chlorine from the reservoir compounds $\mathrm{HCl}$ and $\mathrm{ClONO}_{2}$ to $\mathrm{Cl}_{2}$ (Molina et al., 1987). This process occurs throughout the polar night. When solar radiation reaches the polar lower stratosphere again, $\mathrm{Cl}_{2}$ is photolyzed to active $\mathrm{Cl}$ that participates in a series of catalytic

Correspondence to: C. von Savigny

(csavigny@iup.physik.uni-bremen.de) ozone destruction cycles (e.g. Solomon, 1999). The formation of PSCs requires temperatures of less than about $195 \mathrm{~K}$ for PSC types Ia (NAT, nitric acid tri-hydrate; crystalline) and $\mathrm{Ib}$ (ternary solution of $\mathrm{HNO}_{3}, \mathrm{H}_{2} \mathrm{SO}_{4}$ and $\mathrm{H}_{2} \mathrm{O}$; liquid), and less than about $188 \mathrm{~K}$ for PSC type II $\left(\mathrm{H}_{2} \mathrm{O}\right.$ ice $)$.

Several different techniques were applied in the past to remotely sense PSCs. In terms of ground-based methods there are passive spectrometers measuring scattered solar radiation (e.g. Sarkissian et al., 1994; Enell et al., 1999), as well as active LIDAR systems (e.g. Santacesaria et al., 2001). Satellite remote sensing techniques to detect PSCs include solar occultation (McCormick et al., 1989; Fromm et al., 1997; Nedoluha et al., 2003), stellar occultation (Vanhellemont et al., 2005), limb scattering (von Savigny et al., 2005a), and IR emission spectroscopy (Spang et al., 2005). Groundbased measurements can provide continuous observations with high temporal resolution, but are limited to a certain location. The spatial coverage of satellite observations depends on the method used, but it is a common feature of most satellite methods, that a certain air volume may only be sampled once every several days/weeks. The solar occultation measurements generally provide PSC extinction profiles at different wavelengths with high vertical resolution, but can only be performed during orbital sunsets/sunrises. The geographical coverage of solar occultation measurements on a given day is therefore rather limited. Limb scattering observations are limited to the sunlit part of the Earth, whereas stellar occultation and IR emission can in principle by applied both on the sunlit and the dark side of the Earth.

First results on PSC measurements with SCIAMACHY limb scattering observations were already presented in von Savigny et al. (2005a). In this paper we present a more comprehensive description of the PSC detection method and its performance using the 2003 Southern Hemisphere (SH) PSC season as a sample data set. The paper is structured as follows: in Sect. 2 a brief description of the SCIAMACHY instrument and the limb scattering geometry is given, followed

(C) 2005 Author(s). This work is licensed under a Creative Commons License. 

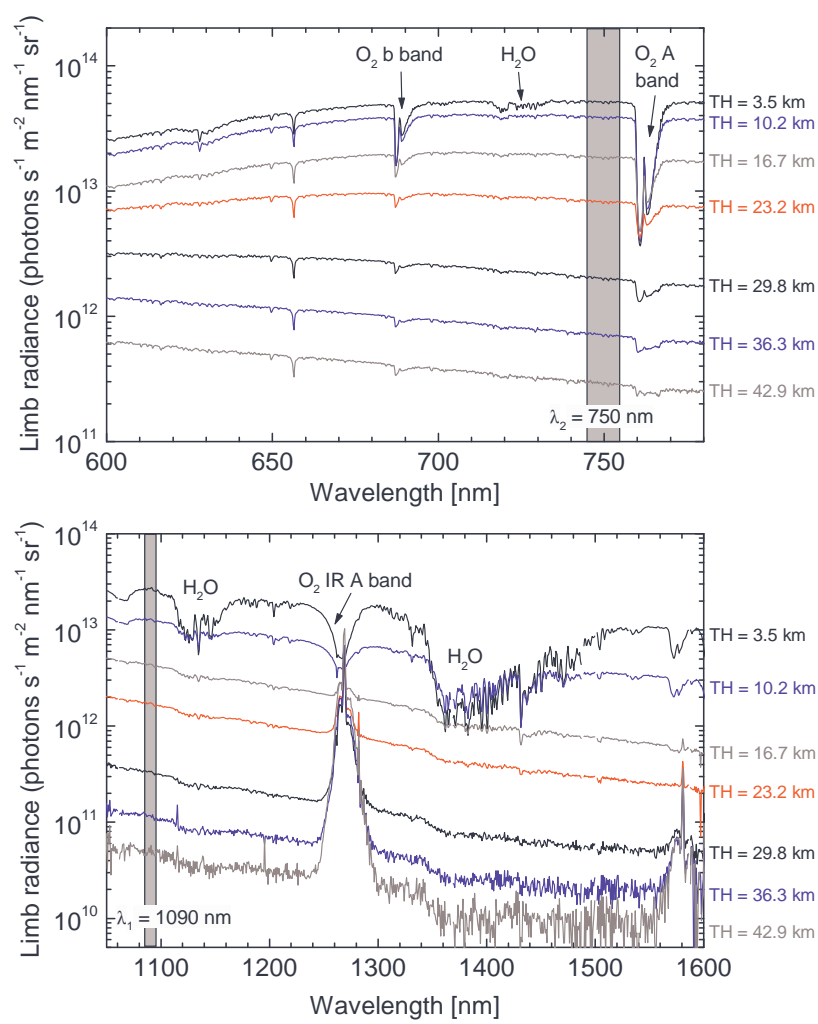

Fig. 1. Limb radiance spectra for SCIAMACHY channels 4 (upper panel) and 6 (lower panel) for a sample limb observation. Large radiances correspond to low tangent heights and vice versa. The most prominent feature in channel 4 is the $\mathrm{O}_{2} \mathrm{~A}$ band at $760 \mathrm{~nm}$, that appears as an absorption feature at low tangent heights and as an emission at higher tangent heights (not shown here). A more detailed description of the spectral features appearing in the spectra can be found in Kaiser et al. (2004).

by a summary of the PSC detection technique in Sect. 3. Results on the SH PSC season of 2003, the temporal change of PSC altitudes, and temperatures at PSC altitudes are presented in Sect. 4.

\section{SCIAMACHY on Envisat}

SCIAMACHY, the Scanning Imaging Absorption spectroMeter for Atmospheric CartograpHY (Bovensmann et al., 1999 ) is one of ten scientific instruments on board the European Space Agency's (ESA) environmental satellite Envisat. Since its successful launch on 1 March, 2002 Envisat orbits the Earth in a polar, sun-synchronous orbit with a 10:00 LST (local solar time) descending node. SCIAMACHY performs spectroscopic observations of scattered, reflected and transmitted solar radiation in three different observation geometries: Nadir, occultation and limb scattering. In this study only SCIAMACHY limb scattering observations are used. In limb viewing mode, the tangent height range from $0 \mathrm{~km}$ to about $100 \mathrm{~km}$ is covered in tangent height steps of $3.3 \mathrm{~km}$. At each tangent height step an azimuthal, i.e., horizontal scan is performed corresponding to $960 \mathrm{~km}$ at the tangent point. The instantaneous field of view in limb mode is about $2.6 \mathrm{~km}$ vertically and $110 \mathrm{~km}$ horizontally at the tangent point. The spectral range from about $220 \mathrm{~nm}$ up to $2380 \mathrm{~nm}$ is covered with a wavelength-dependent spectral resolution of $0.2-1.5 \mathrm{~nm}$. On the sunlit side of the Earth limb and nadir measurements are performed alternately, leading to about 25 limb measurements per orbit. The spatial extent of the limb ground pixels is about $1000 \mathrm{~km}$ perpendicular to the flight (and viewing) direction and $500 \mathrm{~km}$ parallel to the flight direction.

It has to be mentioned that the SCIAMACHY limb measurements during 2003 were affected by pointing errors of up to $3 \mathrm{~km}$ caused by inaccurate knowledge of the spacecraft's attitude and/or position. As a first order pointing correction $1.5 \mathrm{~km}$ were subtracted from the tangent heights provided in the Level 1 data files. More information on the pointing problem can be found in von Savigny et al. (2005b).

\section{Methodology}

PSC particles act as scatterers of solar radiation and therefore affect the measured limb radiance profiles. Since the PSC particle sizes are not small compared to the wavelength of the solar radiation in the UV/Visible/NIR spectral range, the spectral dependence of their scattering coefficient differs from the Rayleigh $\lambda^{-4}$ spectral dependence. Hence, the ratio (i.e., color ratio or color index) of limb radiances at two wavelengths will provide a sensitive indicator for the presence of PSCs. The following aspects have to be considered when selecting a pair of wavelengths suitable for detecting PSCs with a color index approach using limb scattering observations: (a) the wavelengths should not be affected by molecular absorption, or at least as little as possible; (b) the wavelengths must not be shorter than about $400 \mathrm{~nm}$, since the atmosphere becomes optically thick at UV wavelengths for lower stratospheric tangent heights. This is because of the $\lambda^{-4}$ wavelength dependence of Rayleigh scattering and below $320 \mathrm{~nm}$ also because of the absorption in the Huggins and Hartley bands of $\mathrm{O}_{3}$. Please note that $400 \mathrm{~nm}$ is only an approximate threshold. The longer the wavelength, the larger is the altitude range where the atmosphere between the tangent point and the instrument is optically thin in terms of Rayleigh extinction.

The following wavelengths were chosen: $\lambda_{1}=1090 \mathrm{~nm}$ (SCIAMACHY channel 6) which is just short of a $\mathrm{H}_{2} \mathrm{O}$ absorption band ranging from about $1100 \mathrm{~nm}$ to $1170 \mathrm{~nm}$; $\lambda_{2}=750 \mathrm{~nm}$ (SCIAMACHY channel 4) between a $\mathrm{H}_{2} \mathrm{O}$ absorption band centered at $725 \mathrm{~nm}$ and the $\mathrm{O}_{2}$ A-band $\left(b^{1} \Sigma_{g}^{+} \rightarrow X^{3} \Sigma_{g}^{-}\right)$band at around $760 \mathrm{~nm}$. In order to improve the signal to noise ratio we used radiances integrated 
over $\pm 5 \mathrm{~nm}$ intervals around $\lambda_{1}$ and $\lambda_{2}$. Figure 1 shows sample limb radiance spectra for channels 4 and 6 .

In a first step the color index of the limb radiances $\mathrm{I}(\lambda, \mathrm{TH})$ at $\lambda_{1}$ and $\lambda_{2}$ is simply determined by

$$
R_{c}(\mathrm{TH})=\frac{I\left(\lambda_{1}, \mathrm{TH}\right)}{I\left(\lambda_{2}, \mathrm{TH}\right)}
$$

with TH denoting the tangent height. This approach is similar to the one used for PSC detection with ground-based UV/Visible spectrometers (e.g. Sarkissian et al., 1994).

In a second step a color index ratio $\Theta(\mathrm{TH})$ between two adjacent tangent heights is determined from the color index profiles:

$$
\Theta(\mathrm{TH})=R_{c}(\mathrm{TH}) / R_{c}(\mathrm{TH}+\Delta \mathrm{TH})
$$

where $\Delta \mathrm{TH}=3.3 \mathrm{~km}$ is the SCIAMACHY tangent height step. PSCs are detected if the color index ratio $\Theta(\mathrm{TH})$ exceeds a certain threshold. Figure 2 shows color index profiles $R_{c}(\mathrm{TH})$ and color index ratio profiles $\Theta(\mathrm{TH})$ for two sample measurements with and without PSCs in the field of view. The use of the color index ratio instead of the color index has proven advantageous, since the color index ratio can be forward-modeled with radiative transfer (RT) calculations even if the measurements are not calibrated. Therefore, radiative transfer calculations can be used as a guide to find an optimum threshold for PSC detection. In order to estimate the range of color index ratios $\Theta(\mathrm{TH})$ occurring in a PSC-free stratosphere - only due to Rayleigh scattering and stratospheric sulphate aerosol - we performed simulations with the RT model LIMBTRAN (Griffioen and Oikarinen., 2000) for the following scenarios: (a) a pure Rayleigh atmosphere without aerosols, (b) stratospheric background aerosol conditions, (c) moderate volcanic and (d) high volcanic aerosol conditions and for the solar zenith angle (SZA) range from $30^{\circ}$ to $90^{\circ}$, and the solar azimuth angle (SAA) range from $20^{\circ}$ (forward scattering) to $160^{\circ}$ (backward scattering). These SZA and SAA ranges include all possible SCIAMACHY limb viewing geometries. The standard MODTRAN aerosol extinction coefficient profiles were used and a Henyey-Greenstein phase function with an asymmetry parameter of $g=0.7$.

Figure 3 shows contour plots of the modeled maximum color index ratios $\Theta(\mathrm{TH})$ between 12 and $30 \mathrm{~km}$ altitude for the stratospheric aerosol scenarios (a)-(d). The maximum modeled color index ratio $\Theta(\mathrm{TH})$ for the possible SCIAMACHY viewing angles are 1.1 for case (a), 1.2 for case (b), 1.3 for case (c), and 1.7 for case (d) for the 15 to $30 \mathrm{~km}$ altitude range. Therefore, the threshold for PSC detection requires some a priori knowledge of the stratospheric aerosol loading. For the present study - for a low stratospheric aerosols loading - a PSC detection threshold for the color index ratio of $\Theta=1.3$ was employed. This implies that optically thin PSCs may not be detected, and the derived statistics is somewhat biased to optically thicker PSCs. Lower color index ratio threshold values $(\Theta=1.15,1.2,1.25)$ were also

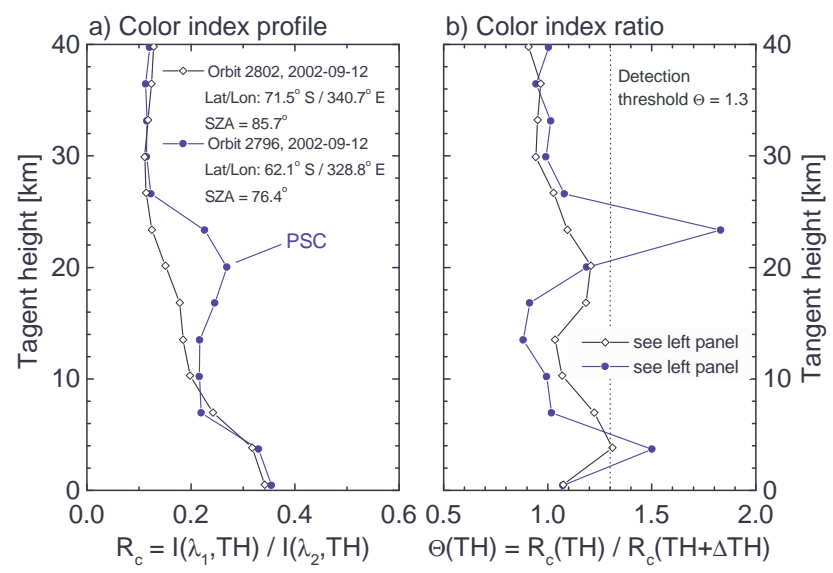

Fig. 2. Sample color index profiles (left panel; $\lambda_{1}=1090 \mathrm{~nm}$, $\lambda_{2}=750 \mathrm{~nm}$ ) and color index ratio profiles (right panel) for limb scattering measurements with and without PSCs in the field of view.

tested and led to a significant number of spurious PSC detections. Also shown in Fig. 3 are the viewing angles of SCIAMACHY limb measurements on different days in Southern Hemisphere Winter/Spring 2003.

Most aspects of the viewing angle dependence of the modeled color index ratios in Fig. 3 can be understood qualitatively.

- For a fixed SZA the Rayleigh scattering phase function is symmetrical with respect to $\mathrm{SAA}=90^{\circ}$, whereas the Mie-phase function favors forward scattering. Therefore, we expect the contour plot for the Rayleigh-only scenario (a) to be more symmetrical with respect to an azimuth angle of $90^{\circ}$ than the scenarios (b)-(d). Figure 3 shows that this is the case.

- For enhanced stratospheric aerosol loading (scenarios c and d) the asymmetry of the Mie phase function will become more important, leading to small color index ratios for large solar azimuth angles (backward scattering) and large color index ratios for small solar azimuth angles (forward scattering).

- In all four cases, the maximum color index ratios increase for setting sun, i.e., if the SZA approaches $90^{\circ}$. This is due to the fact, that the Rayleigh extinction coefficient and generally also the Mie-extinction coefficient at $750 \mathrm{~nm}$ is larger than at $1090 \mathrm{~nm}$. Therefore, the atmosphere is optically thicker at $750 \mathrm{~nm}$ than at $1090 \mathrm{~nm}$ and the color index ratio increases as the SZA approaches $90^{\circ}$.

In order to avoid false PSC identifications due to ordinary cirrus clouds it was required that the enhancement in the color index ratios has to occur at least $3 \mathrm{~km}$ above the climatological tropopause heights taken from Randel et al. (2000). 

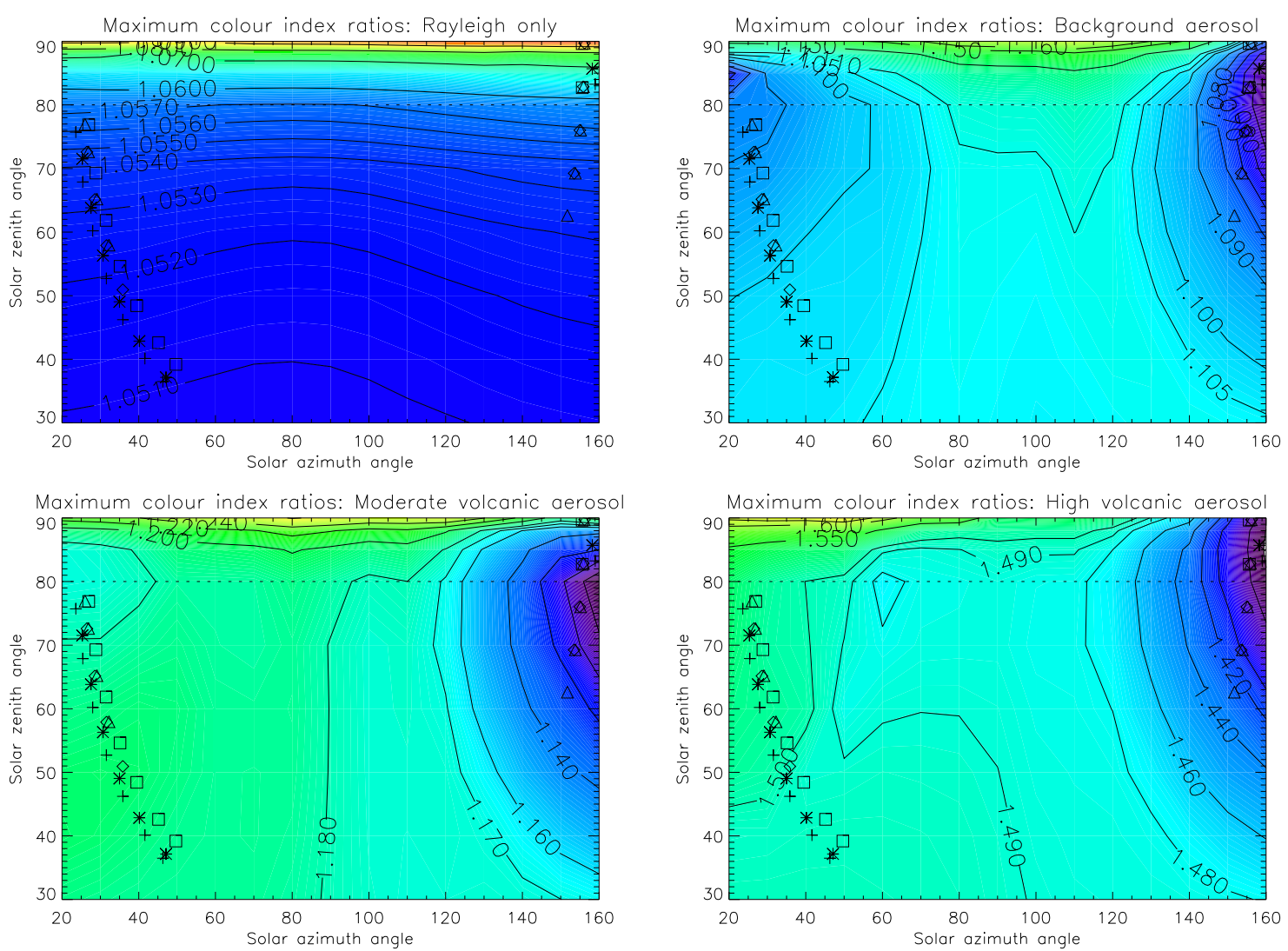

Fig. 3. Modeled maximum color index gradients $\Theta(\mathrm{TH})$ - between 12 and $30 \mathrm{~km}$ altitude - for different stratospheric aerosol loadings as a function of the limb observation angles: solar zenith angle (SZA) and solar azimuth angle (SAA). At $\mathrm{SZA}=90^{\circ} \mathrm{SAA}=0^{\circ}$ corresponds to forward scattering and SAA $=180^{\circ}$ to backward scattering. For the simulations SZA and SAA were varied in steps of $10^{\circ}$ except for SZA $>80^{\circ}$, where the SZA was varied in steps of $2^{\circ}$. The symbols correspond to the viewing angles of the SCIAMACHY measurements on 15 June (plus signs), 15 July (asterisks), 15 August (squares), 15 September (diamonds), and 15 October 2003 (triangles) for latitudes poleward of $50^{\circ}$ (for measurements in the northern/southern hemisphere SAA $<90^{\circ} />90^{\circ}$ ).

The advantages of this PSC detection method are (a) that the threshold for PSC detection can be determined independently with radiative transfer calculations, and (b) that no additional temperature threshold (e.g., $T<200 \mathrm{~K}$ as in Poole and Fritts, 1994) has to be imposed. In terms of (a), the PSC detection methods applied to solar occultation measurements (Poole and Fritts, 1994; Fromm et al., 1997; Hayashida et al., 2000), require empirical aerosol extinction profiles without PSCs to determine the natural variability.

\section{Results and discussion}

In order to show that the aerosol signatures identified in the limb radiance measurements are indeed caused by PSCs we investigate in the following sections the geographical distribution, the temporal and latitudinal variation of the derived PSC altitudes as well as the temperatures at the altitude of the detected PSCs during the 2003 PSC season in the Southern Hemisphere.

\subsection{PSC maps}

PSC maps for the Southern Hemisphere on selected days between June and November 2003 are shown in Fig. 4. The circles indicate locations of SCIAMACHY limb scattering observations. Black solid circles correspond to measurements without PSC detections and the open circles show detected PSCs. The underlying color contours show the UKMO temperature fields for the corresponding days at the $550 \mathrm{~K}$ potential temperature level. The temperature field is an approximate indicator as to where PSCs can be expected. However, $550 \mathrm{~K}$ (about $22 \mathrm{~km}$ ) is generally not identical to the PSC altitude - as will be shown in Sect. 4.2 the PSCs descend slowly as the winter progresses. Therefore, apparent outliers - e.g., the PSCs detected almost above the south pole on 27 September, 2003 at temperatures between $200 \mathrm{~K}$ and $205 \mathrm{~K}$ temperature - are not necessarily PSC occurrences at unrealistically high temperatures. Only up to 10 of the 14 daily orbits are shown for the individual days in Fig. 4. This is because not all the orbits measured are currently available for analysis at IUP/IFE Bremen. 

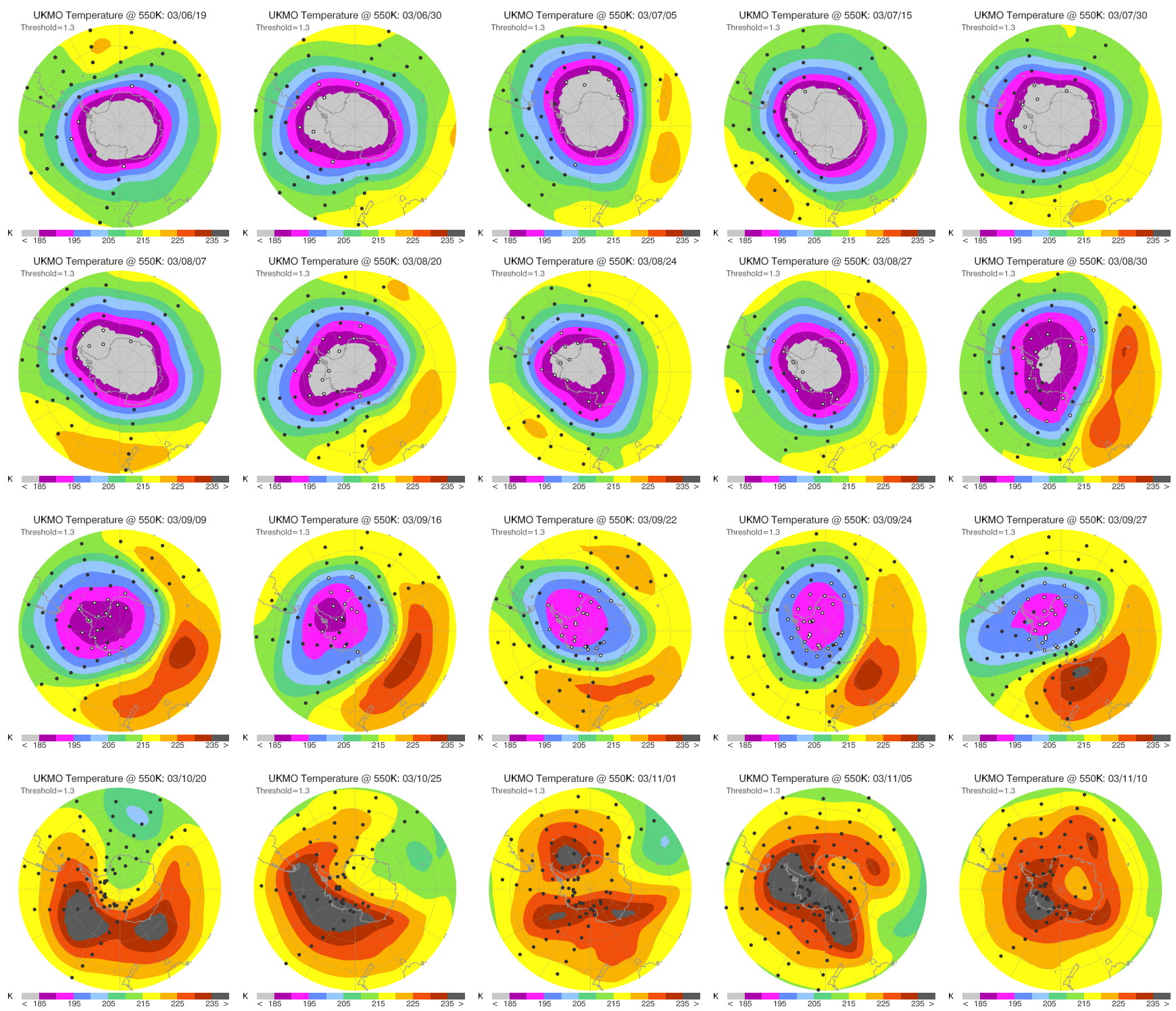

Fig. 4. PSC maps for the Southern Hemisphere for selected days during June to November 2003. The circles correspond to the locations of SCIAMACHY limb scattering measurements. Detected PSCs are indicated by white circles. The underlying color contours represent the UKMO temperatures on the corresponding days at the $550 \mathrm{~K}$ (about $22 \mathrm{~km}$ altitude) potential temperature level. Note, that this level is not in all cases identical to the PSC altitude. First row: June, July; second row: August; third row: September; last row: October and November 2003.

For most days, the detected PSCs occur within the area of sufficiently low temperatures, i.e., roughly below $195 \mathrm{~K}$. The shape of the area covered by PSCs nicely tracks the slowly rotating area of the lower stratospheric temperature minimum. For example, on 20 August 2003 both the vortex and the PSC covered area are slightly elongated and oriented parallel to the $60^{\circ}-240^{\circ}$ meridian. A week later on $27 \mathrm{Au}$ gust 2003 the vortex and the PSC covered area have rotated by about $90^{\circ}$.

Thus, PSCs are detected in the expected Antarctic regions for sufficiently low temperatures. Note, that due to the used detection method thin PSCs may not be detected. A potential improvement would be the use of color index ratio detection thresholds that are a function of the SZA.

\subsection{Temporal evolution of PSC altitude}

By "PSC altitude" we mean the top tangent height for which the color index ratio $\Theta(\mathrm{TH})$ exceeds the threshold of $\Theta=1.3$. Since it contains no information about the vertical extension of the PSC, the PSC altitude is a measure for the PSC top altitude and not for the mean PSC altitude. Note that the actual PSC top altitude will be larger - roughly by about half 

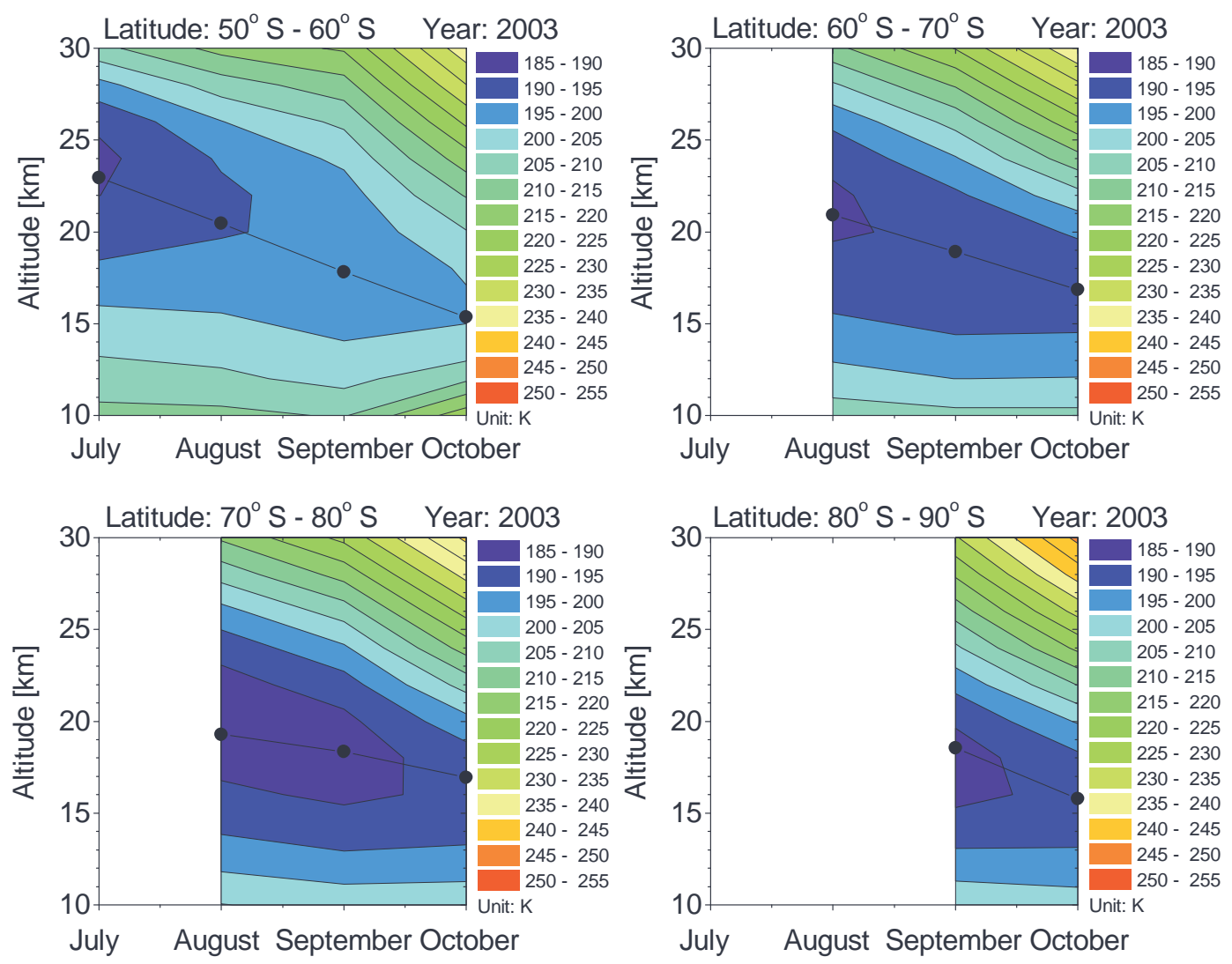

Fig. 5. Temporal evolution of mean PSC altitudes for different latitude bands superimposed to the averaged UKMO temperature profiles at the locations of the SCIAMACHY limb measurements.

a tangent height step, i.e., 1.5 to $2 \mathrm{~km}$ - than the PSC altitudes shown here, since we use the $\mathrm{TH}$, where the color index ratio exceeds $\Theta=1.3$ to determine the PSC altitude.

Figure 5 shows the temporal change of the monthly mean and zonally averaged PSC altitudes for different latitude bands. The latitudinal variation of the monthly mean zonally averaged PSC altitudes is shown in Fig. 6 for July to October 2003. For the higher latitude ranges SCIAMACHY limb measurements were possible only later in the SH winter/spring (see incomplete coverage in Fig. 5), since the high latitude air volumes were not illuminated before.

The color contours show the corresponding mean UKMO temperature field determined by averaging the UKMO temperature profiles extracted for the date, time and location of each individual PSC observation. Obviously both the PSC altitudes and the altitude of the temperature minimum descend slowly with time, and these altitudes are in very good agreement.

The slow descent of PSCs as the winter progresses has also been reported in other studies, using ground-based LIDAR and solar occultation measurements. Santacesaria et al. (2001) report on a 9 year (1989-1997) PSC climatology based on LIDAR observations at the French Antarctic base in Dumont d'Urville $\left(66.40^{\circ} \mathrm{S}, 140.01^{\circ} \mathrm{E}\right)$. The authors dis- cuss three possible reasons for the PSC descent. First, the sedimentation of the PSC particles, which - stated by Santacesaria et al. (2001) - can be excluded as an explanation for the apparent descent, since the sedimentation speeds are too large. PSC type II particles can indeed reach sedimentation velocities on the order of $1 \mathrm{~km} / \mathrm{day}$, which is significantly larger than the observed PSC descent rates. However, the sedimentation velocities of type I PSCs are smaller - as small as $10 \mathrm{~m} /$ day - and may be consistent with an apparent PSC descent rate of $1.5-2.5 \mathrm{~km} / \mathrm{month}$. Secondly, the slow diabatic descent of the $\mathrm{HNO}_{3}$ and $\mathrm{H}_{2} \mathrm{O}$ distributions. This process leads to descent rates of less than $0.5 \mathrm{~km} /$ month, and is therefore not strong enough to solely cause the observed descent. Thirdly, the descent of the lower stratospheric temperature minimum. Our PSC observations together with the UKMO temperature data strongly indicate that the stratospheric temperature is the main driver for the PSC descent.

The PSC descent rates derived from our measurements for 2003 are: $2.5 \mathrm{~km} /$ month for the $50^{\circ} \mathrm{S}-60^{\circ} \mathrm{S}$ latitude band, $2.0 \mathrm{~km} / \mathrm{month}$ for the $60^{\circ} \mathrm{S}-70^{\circ} \mathrm{S}$ latitude band, and $1.2 \mathrm{~km} /$ month for latitudes between $70^{\circ} \mathrm{S}$ and $80^{\circ} \mathrm{S}$. Interestingly, the descent rates increase with decreasing latitude. These values are in very good agreement with the LIDAR measurements by Santacesaria et al. (2001) at Dumont 

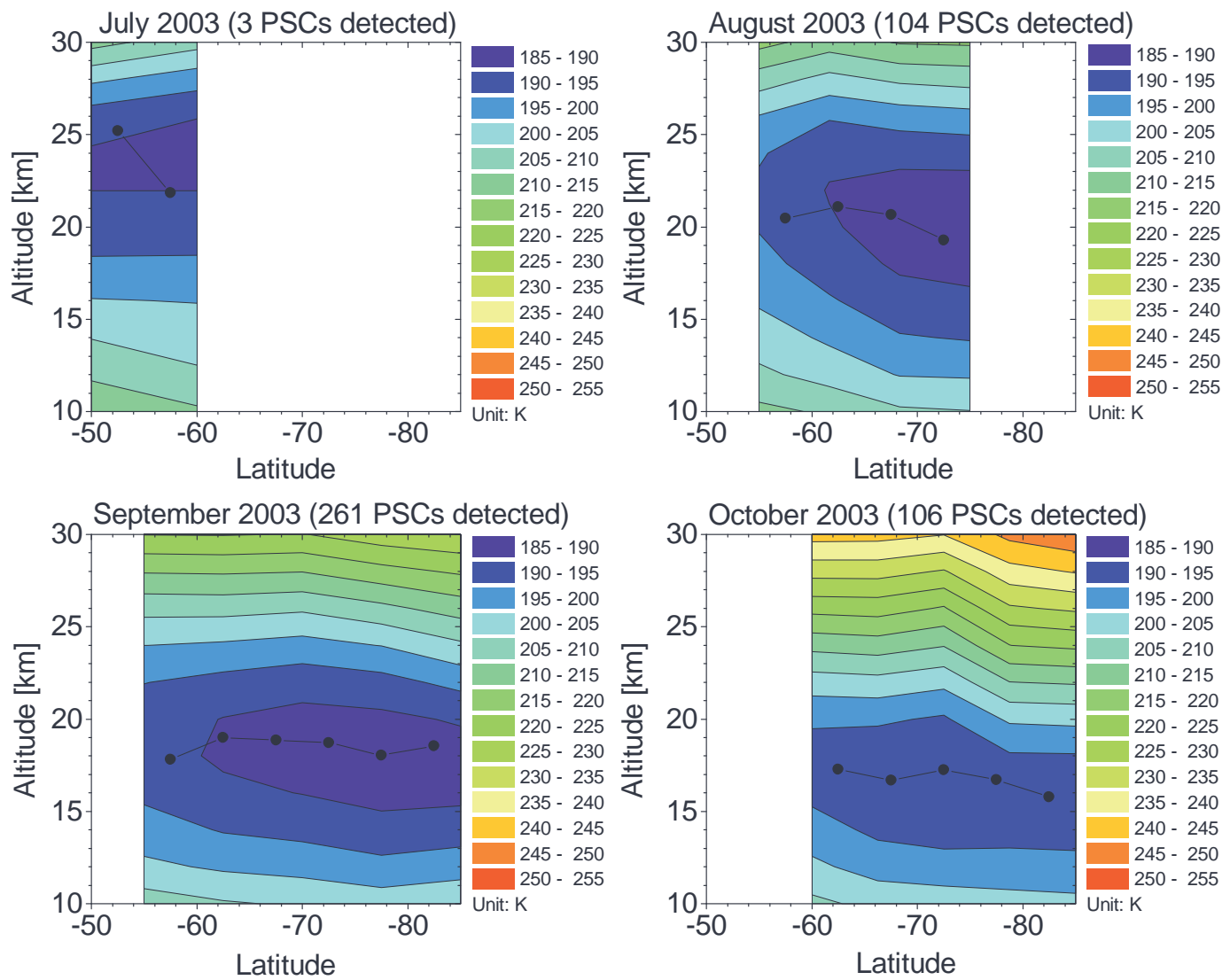

Fig. 6. Latitude dependence of mean PSC altitudes for different months of the year 2003 superimposed to the averaged UKMO temperature profiles at the locations of the SCIAMACHY limb measurements.

d'Urville yielding about $2.0-2.5 \mathrm{~km} / \mathrm{month}$. It is important to note, that we use a derived PSC altitude that is more representative for the PSC top altitude, whereas Santacesaria et al. (2001) show mid-cloud altitudes. However, Santacesaria et al. (2001) mention explicitly that the descent rates derived from the cloud tops do not differ significantly from the mid-cloud altitude descent rates. A PSC descent with rates of about $2.0 \mathrm{~km} /$ month was also observed in POAM II solar occultation measurements (Fromm et al., 1997) during Southern Hemisphere springs of 1994-1996. The latitudes of the occultation observations varied slowly between about $65^{\circ} \mathrm{S}$ and $88^{\circ} \mathrm{S}$ from June to October. Vanhellemont et al. (2005) recently presented measurements of the extinction by stratospheric background aerosols and PSCs with GOMOS (Global Ozone Monitoring by Occultation of Stars), another remote sensing instrument on Envisat. Although no PSC descent rates were derived, the observed PSC descent is in good agreement with the results presented here.

From the very good agreement of descent rates of the temperature minimum and the PSC descent rates derived in this study it appears that the temporal variation of the lower stratospheric temperature structure is the main driver of the PSC descent.

\subsection{Distribution of temperature at PSC altitudes}

Generally, type I PSCs are assumed to form at temperatures below about $195 \mathrm{~K}$, and type II PSCs at temperatures below $188-190 \mathrm{~K}$. It is important to realize that these threshold temperatures are not constant, but depend on the amount of the molecular species the PSC are composed of, i.e., $\mathrm{HNO}_{3}$, $\mathrm{H}_{2} \mathrm{SO}_{4}$ and $\mathrm{H}_{2} \mathrm{O}$. For all PSCs detected in 2003 the temperature at the PSC altitudes and their locations were extracted from the UKMO temperature fields and are presented as histograms for different months in Fig. 7. July 2003 is not shown here, since only 3 PSCs were detected in this month. This low number is due to the fact that the SH polar cap was not illuminated and therefore SCIAMACHY limb scattering measurements were not possible. The average temperatures at the PSC altitudes are around $190 \mathrm{~K}$ in August, September, and October 2003, and assume a minimum value of $189.5 \mathrm{~K}$ in September. In November no PSCs were detected in agreement with temperatures of generally more than $215 \mathrm{~K}$ at the $550 \mathrm{~K}$ potential temperature level (see Fig. 4). The derived temperatures of around $190 \mathrm{~K}$, at which PSCs are most likely to occur are in very good agreement with previous studies. Santacesaria et al. (2001) report the highest PSC occurrence frequency at a temperature of $189 \mathrm{~K}$. Poole and Fritts (1994) 

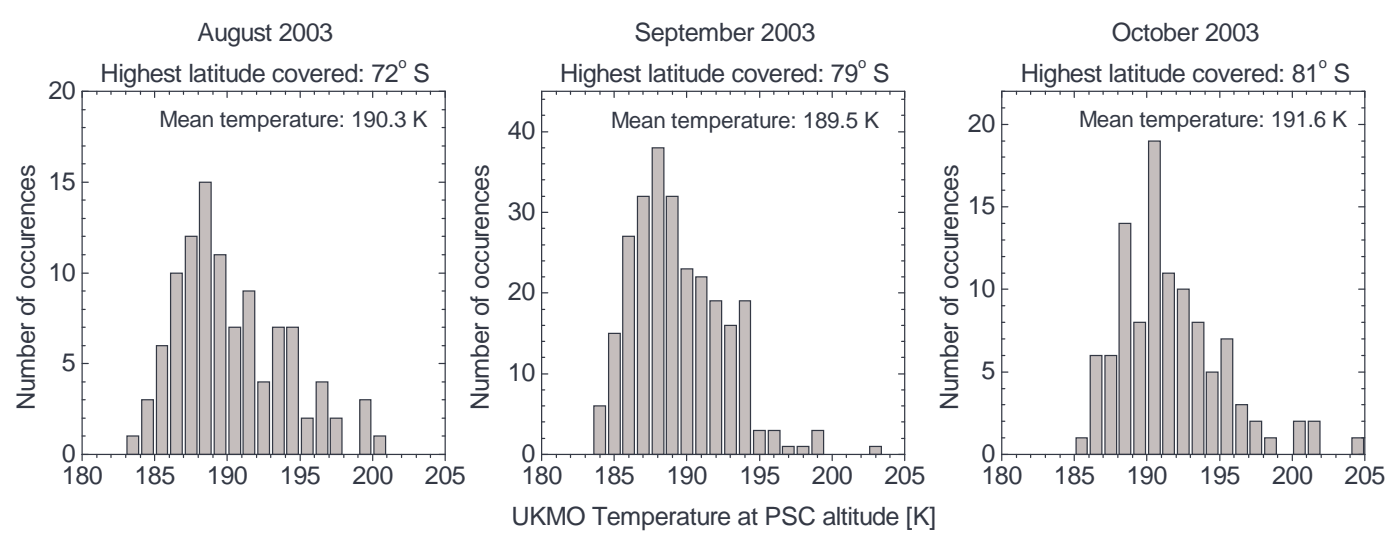

Fig. 7. Distribution of the (UKMO) temperatures at the derived PSC locations and altitudes for August, September and October 2003. The mean temperatures at PSC altitude is around $190 \mathrm{~K}$ for all three months, and the majority of the detected PSCs occurs at temperatures below $195 \mathrm{~K}$.

find the highest PSC occurrence frequency at $190 \mathrm{~K}$ using a 12 years of SAGE II PSC observations. Note, that the low PSC occurrence numbers below temperatures of about $185 \mathrm{~K}$ are not due to PSCs not forming at these temperatures, but because only few SCIAMACHY limb scattering observations at locations with lower temperatures are made. The limb scattering observations are limited to the sunlit part of the atmosphere, and therefore the highest southern latitudes with extremely low temperatures during polar night cannot be observed.

The majority of the detected PSCs occurred at temperatures of less than $195 \mathrm{~K}$, in good agreement with the expectation. There were a few detections at higher temperatures, that may be a consequence of different reasons: (a) due to remaining errors in the SCIAMACHY limb pointing, the PSCs actually occurred at slightly different altitudes, and therefore different temperatures; (b) larger abundances of the molecular species the PSCs consist of, so that the existence of particles can be maintained at higher temperatures; (c) possibly small errors in the UKMO temperatures (Pullen and Jones, 1997). In total there were only 7 PSCs detected at apparent temperatures above $200 \mathrm{~K}$. None of them occurred at temperatures higher than $205 \mathrm{~K}$.

\section{Discussion and conclusions}

In this manuscript we have investigated the detection of PSCs and for the first time the temporal variation of PSC altitudes using limb scattering measurements. This has been achieved with a limited number of wavelengths. As the in-flight calibration of SCIAMACHY is improved, we anticipate the extension of the wavelength range to be used to study stratospheric aerosol, PSCs, and cirrus clouds. PSC type II and cirrus clouds consist of ice particles. In this respect a phase index approach has already been demonstrated to allow the distinction of tropospheric liquid water and ice clouds us- ing Nadir measurements at wavelengths around 1.6 micron (Kokhanovsky et al., 2005). There are several other regions where liquid water and ice absorb in the 0.7-2.4 micron region. These absorption signatures may be employed for the detection of type II PSCs. This, as well as the use of SCIAMACHY polarization measurements, is presently under investigation. Another important question is whether the SCIAMACHY limb scattering observations with their wide spectral range allow the distinction between type Ia and type Ib PSCs. The principal constituents, i.e., $\mathrm{HNO}_{3}$ and $\mathrm{H}_{2} \mathrm{SO}_{4}$ have no usable absorption/emission features in the SCIAMACHY spectral range. However, the derivation of PSC particle radii - which is easily possible with noctilucent clouds (NLCs) in the UV spectral range (von Savigny et al., 2004), where the strong absorption of solar radiation in the Hartley and Huggins bands of $\mathrm{O}_{3}$ lead to negligibly small multiple scattering and surface reflection contributions - in combination with the measurements of the degree of linear polarization may allow to distinguish between type Ia and Ib. This is also the subject of ongoing investigations.

In summary, a method to detect PSCs from limb scattering observations in the Visible/NIR spectral range was presented. The method is based on a color index approach and has been applied to SCIAMACHY limb scattering measurements during the 2003 PSC season in the Southern Hemisphere. PSC descent rates of $1.0-2.5 \mathrm{~km} /$ month were derived, and descent rates were found to increase with increasing latitude. The good correlation between PSC altitude and the altitude of the lower stratospheric temperature minimum leads to the conclusion that the temporal change of the stratospheric temperature field is the main driver behind the observed descent. Concluding, satellite measurements of limb-scattered solar radiation in the Visible/NIR spectral range are a sensitive technique to detect and map PSCs.

Acknowledgements. We thank the European Space Agency (ESA) for providing the SCIAMACHY data used in this study, the United Kingdom Meteorological Office (UKMO) for providing the UKMO 
model data, and Erik Griffioen for making LIMBTRAN available to us. Furthermore, we are indebted to the entire SCIAMACHY team whose efforts make all scientific data analysis possible. This work was in part funded by the University of Bremen and by the German Ministry of Education and Research BMBF (grant 07UFE12/8) and the German Aerospace Center (grant 50EE0027).

Edited by: P. C. Simon

\section{References}

Bovensmann, H., Burrows, J. P., Buchwitz, M., Frerick, J., Noël, S., Rozanov, V. V., Chance, K. V., and Goede, A. P. H.: SCIAMACHY: Mission objectives and measurement modes, J. Atmos. Sci., 56(2), 127-150, 1999.

Enell, C.-F., Steen, A., Wagner, T., Frieß, U., and Platt, U.: Occurrence of polar stratospheric clouds at Kiruna, Ann. Geophys., 17, 1457-1462, 1999,

\section{SRef-ID: 1432-0576/ag/1999-17-1457.}

Fromm, M. D., Bevilacqua, R. M., Lumpe, J. D., Shettle, E. P., Hornstein, J. S., Massie, S. T., and Fricke, K.-H.: Observations of Antarctic polar stratospheric clouds by POAM II: 1994-1996, J. Geophys. Res., 102, 23 659-23 672, 1997.

Farman, J. C., Gardiner, B. G., and Shanklin, J. D.: Large Losses of Total Ozone in Antarctica Reveal Seasonal $\mathrm{ClO}_{\mathrm{x}} / \mathrm{NO}_{\mathrm{x}}$ Interaction, Nature, 315, 207-210, 1985.

Griffioen, E. and Oikarinen, L.: LIMBTRAN: A pseudo threedimensional radiative transfer model for the limb-viewing imager OSIRIS on the Odin satellite, J. Geophys. Res., 105, D24, 29717-29730, 2000.

Hayashida, S., Saitoh, N., Kagawa, A., Yokota, T., Suzuki, M., Nakajima, H., and Sasano, Y.: Arctic polar stratospheric clouds observed with the Improved Limb Atmospheric Spectrometer during winter 1996/1997, J. Geophys. Res., 105, 24 715-24 730, 2000.

Kaiser, J. W., Eichmann, K.-U., Noël, S., Wuttke, M. W., Skupin, J., von Savigny, C., Rozanov, A. V., Rozanov, V. V., Bovensmann, H., and Burrows, J. P.: SCIAMACHY limb spectra, Adv. Space Res., 34(4), 715-720, 2004.

Kokhanovsky, A. A., Rozanov, V. V., Burrows, J. P., Eichmann, K.U., Lotz, W., and Vountas, M.: The SCIAMACHY cloud products: algorithms and examples from ENVISAT, Adv. Space Res., in press, 2005.

McCormick, M. P., Trepte, C. R., and Pitts, M. C.: Persistence of Polar Stratospheric Clouds in the Southern Polar Region, J. Geophys. Res., 94, 11 241-11 251, 1989.

Molina, M. J., Tso, T. L., Molina, L. T., and Wang, F. C.-Y., Antarctic Stratospheric Chemistry of Chlorine Nitrate, Hydrogen Chloride and Ice: Release of Active Chlorine, Science, 238, 12531257, 1987.

Nedoluha, G. E., Bevilaqua, R. M., Fromm, M. D., Hoppel, K. W., and Allen, D. R.: POAM measurements of PSCs and water vapor in the 2002 Antarctic vortex, Geophys. Res. Lett., 30(15), 1796, doi:10.1029/2003GL017577, 2003.
Poole, L. R. and Pitts, M. C.: Polar stratospheric cloud climatology based on stratospheric aerosol measurement II observations from 1978 to 1989, J. Geophys. Res., 99, 13 083-13 089, 1994.

Pullen, S. and Jones, R. L.: Accuracy of temperatures from UKMO analyses of 1994/1995 in the Arctic winter stratosphere, Geophys. Res. Lett., 24, 845-848, 1997.

Randel, W. J., Wu, W., and Gaffen, D.: Interannual variability of the tropical tropopause derived from radiosonde data and NCEP reanalyses, J. Geophys. Res., 105, 15 509-15 523, 2000.

Santacesaria, V., MacKenzie, A. R., and Stefanutti, L.: A climatological study of polar stratospheric clouds (1989-1997) from LIDAR measurements over Dumont d'Urville (Antarctica), Tellus, 53B, 306-321, 2001.

Sarkissian, A., Pommereau, J.-P., and Goutail, F.: PSC and volcanic aerosol observations during EASOE by UV-visible ground-based spectroscopy, Geophys. Res. Lett., 21, 1319-1322, 1994.

Solomon, S.: Stratospheric ozone depletion: A review of concepts and history, Reviews of Geophysics, 37, 275-316, 1999.

Spang, R., Remedios, J. J., Kramer, L. J., Poole, L. R., Fromm, M. D., Müller, M., Baumgarten, G., and Konopka, K.: Polar stratospheric cloud observations by MIPAS on Envisat: detection method, validation and analysis of the northern hemisphere winter 2002/2003, Atmos. Chem. Phys., 5, 679-692, 2005,

SRef-ID: 1680-7324/acp/2005-5-679.

Vanhellemont, F., Fussen, D., Bingen, C., Kyrölä, E., Tamminen, J., Sofiefa, V., Hassinen, S., Verronen, P., Seppälä, A., Bertaux, J. L., Hauchecorne, A., Dalaudier, F., Fanton d'Andon, O., Barrot, G., Mangin, A., Theodore, B., Guirlet, M., Renard, J. B., Fraisse, R., Snoeij, P., Koopman, R., and Saavedra, L.: A 2003 stratospheric aerosol extinction and PSC climatology from GOMOS measurements on Envisat, Atmos. Chem. Phys., 5, 2413-2417, 2005 ,

SRef-ID: 1680-7324/acp/2005-5-2413.

von Savigny, C., Kokhanovsky, A., Bovensmann, H., Eichmann, K.-U., Kaiser, J. W., Noël, S., Rozanov, A. V., Skupin, J., and Burrows, J. P.: NLC detection and particle size determination: first results from SCIAMACHY on Envisat, Adv. Space Res., 34(4), 851-856, 2004.

von Savigny, C., Rozanov, A., Bovensmann, H., Eichmann, K.-U., Noël, S., Rozanov, V. V., Sinnhuber, B.-M., Weber, M., and Burrows, J. P.: The ozone hole break-up in September 2002 as seen by SCIAMACHY on Envisat, J. Atmos. Sci., 62(3), 721-734, 2005a.

von Savigny, C., Kaiser, J. W., Bovensmann, H., Burrows, J. P., McDermid, I. S., and Leblanc, T.: Spatial and temporal characterization of SCIAMACHY limb pointing errors during the first three years of the mission, Atmos. Chem. Phys., 5, 2593-2602, 2005b,

SRef-ID: 1680-7324/acp/2005-5-2593. 